\title{
Gendered Lives: Gender Inequalities in Production and Reproduction
}

\author{
edited by Jacqueline Scott, Shirley Dex, and Anke C. Plagnol \\ Cheltenham: Edward Elgar 2012 \\ ISBN 978-1-84980-626-8 \\ Softcover, £69.95, $231 \mathrm{pp}$.
}

\author{
Reviewed by Susan McDaniel \\ University of Lethbridge
}

With a focus on gendered lives, this edited book takes a dual stance not only in analyzing changes in gendered lives, but considering as well how further change towards greater gender equality might be achieved. The Editors aim to push what they term the "well-worked field" of gender inequality in new, innovative, and timely directions. To achieve this, the chapters in this volume all take a life-course perspective, relying on longitudinal analyses. Their approach is dynamic, in analyzing how both individuals and social institutions "do gender." Time, technology, and social, familial, and policy changes are taken into consideration. The geographic focus is largely the UK. The book is the product of a five-year research initiative, where researchers from varying disciplines with different theoretical stances and reliance on different methodologies met to together attempt to answer a set of questions about gendered lives. The presumption of this process was that the sum of the interactions over time would exceed that of individual efforts.

The book is divided into three sections, preceded by an unnumbered introduction: gendered lives unfolding across time, gender inequalities in the household and workplace, and gender inequalities in a changing world. Eight chapters comprise the book, all written by well established researchers, mostly from the UK. There is no concluding chapter.

The introduction highlights the overarching stance of the book, describes trends in gender inequality and equality in the UK, and then summarizes some of the major findings of the research, focusing on the unexpected. Of the latter, two are brought to the fore in the introduction. First is the finding from research by John Hobcraft and Wendy Sigle-Rushton (Chapter 1), based on two-point-in-time analyses of national studies in Britain, comparing cohorts born in 1958 with those born in 1970 to see whether there are common predictors of adult disadvantage by gender. Adult outcomes are consistently found to be linked to childhood experiences, but the surprise finding is that although women are more likely to be disadvantaged as adults than men-a well known reality - the mechanisms that link childhood experiences with adult outcomes are found to be similar for men and women. This suggests that a complex interplay is involved of gender with social institutions and factors, with the need for a more nuanced approach to capturing the dynamics of gender inequalities across the life course.

The second unexpected finding highlighted in the introduction comes from multi-method research by Fran Bennett, Jerome De Henau, Susan Himmelweit, and Sirin Sung on the processes by which heterosexual couples work out their household finances (Chapter 4). Little is known about how household income is shared by couples, although it is widely presumed, particularly by policy, that income is shared equally. What is found is that gender roles in couples matter to how satisfied couples are with their household income. For both men and women, the job of the man matters more.

Other interesting findings also emerge from the research reported in this book. For example, in examining changing career trajectories of men and women over time, Erzsebet Bukodi, Shirley Dex, and Heather Joshi 
(Chapter 2) find that a shift has indeed occurred towards greater gender equality, but hidden behind this trend is the growing instability of men's careers, known to be a factor in North America as well. Gender imbalances in the division of labour are found to persist, with institutional and ideological gender expectations lagging behind the real-life demands of society and the workplace (Chapter 3, by Jonathan Gershuny and Man Yee Kan). As Gershuny and Kan emphasize, however, this does not mean that gender change is stalled.

The last chapter in Section II (Chapter 5, by Linda McDowell, Adina Batnitzky, and Sarah Dyer) examines the question of the interactions of gender with other inequalities. They find, through intensive interviews with non-British-born service workers in a hotel and a hospital, as well as with agencies and managers in service sectors that employ transnational workers, that internationalizing labour markets, migration patterns, national origins, gender, and skin colour combine to construct worker profiles for service/care sectors. For example, although some men of colour are in 'feminized work' of caring, cleaning, etc., others are compartmentalized for particular kinds of work: Indian men seen as embodying the colonial traditions of hospitality and service, or Caribbean women associated with nursing. They argue that the global reach of local service sectors is producing new geographies of inequalities in Britain (and other developed countries) that reproduce existing global inequalities.

Chapter 6, by Colm McLaughlin and Simon Deakin, asks whether the business case for addressing gender inequalities is likely to be persuasive, as is commonly argued. Based on interviews with eight public sector and eight private sector organizations, as well as with two universities and two not-for-profit organizations, they find that the evidence is mixed. Increased reliance on diversity management has, in fact, reduced the imperative of gender equality, in part because organizational structures that produce gender inequalities are not interrogated. On the other hand, Jacqueline Scott and Anke C. Plagnol (Chapter 7) find, in comparisons among seven European countries, that a more equitable division of labour has beneficial effects for both women and men. Surprisingly, they discover that women working full-time have similar levels of work-family conflict as men, and that number of work hours had no effect on the well-being of either women or men. Even more surprising is the finding that division of unpaid work at home affects men's but not women's well-being. They encourage policies that nudge along greater male participation in unpaid work, even if it is only symbolic.

Chapter 8, by Jane Lewis, focuses on gender and work-family policies in Europe. She looks at how gender policies often clash with additional policy objectives at times, such as in Germany in 2007, when parental leaves were argued to be needed to increase birthrates. Gender and work-family policies also enter into contentious normative territory of what the role of the state should be in relation to families. Health recommendations, such as those on the merits of breastfeeding, also often conflict with gender equality policies and women's need for employment. Her conclusion is that the mix of policies related to gender inequality and work-family reconciliation needs work and coordination to enhance welfare and opportunities for women, men, and families.

Gendered Lives is a fascinating and innovative smorgasbord of new research, asking key questions about the nature and future of gender inequalities. The research presented is accessible at a senior undergraduate level, with more detail available in appendices for researchers. The chapters, although relying on different methodologies and emanating from different disciplines, do not have the "bumpiness" evident in many edited books. This is a story, unfolding in various ways, that taken together, creates a mosaic of changing gendered lives in the UK in shifting micro and macro contexts. The objectives of the editors to push gender inequality in new innovative and timely directions is met, and met well. This book will be cited by researchers and read by senior university undergraduates and graduate students as a "state of the art" work on gendered lives. The only improvement that could be suggested in this book would have been the addition of a concluding chapter. 